\title{
HIV epidemic among men who have sex with men in India: national scenario of an unfinished agenda
}

This article was published in the following Dove Press journal:

HIVIAIDS - Research and Palliative Care

20 November 2014

Number of times this article has been viewed

\author{
Ugra Mohan Jha' \\ Yujwal Raj' \\ Srinivas Venkatesh' \\ Neeraj Dhingra' \\ Ramesh S Paranjpe ${ }^{2}$ \\ Niranjan Saggurti ${ }^{3}$ \\ 'Department of AIDS Control, \\ Ministry of Health and Family \\ Welfare, Government of India, \\ New Delhi, India; ${ }^{2}$ National AIDS \\ Research Institute, Pune, India; \\ ${ }^{3}$ Population Council, New Delhi, India
}

Correspondence: Niranjan Saggurti HIV and AIDS Program, Population Council, New Delhi I I0003, India Email nsaggurti@popcouncil.org
Background: Although India has demonstrated success in the overall reduction of human immunodeficiency virus (HIV) incidence by $57 \%$ in the past 10 years, its control among men who have sex with men (MSM) remains a critical challenge. This paper describes the current status, geographic variability, and factors associated with HIV among MSM from the national perspective.

Methods: Data on the levels and trends of HIV seropositivity and associated risk behaviors among MSM were analyzed and presented from the following data sources: 1) annual HIV Sentinel Surveillance (HSS) conducted during 2003-10, 2) two rounds of the high-risk group size estimation conducted in 2005 and 2009, 3) two rounds of the Behavioral Surveillance Survey conducted in 2006 and 2009, and 4) the Integrated Bio-behavioral Assessment Round 2. Data were analyzed according to selected sociodemographic characteristics and sexual identities of MSM to understand the factors associated with high HIV prevalence.

Results: HSS data indicate that at the national level, HIV prevalence among MSM overall is declining (from $12.3 \%$ in 2003 to $4.43 \%$ in 2010). However, marginal increasing trends were observed in Chandigarh (from 1.4\% in 2004 to 2.8\% in 2008) and Haryana (from $0 \%$ in 2006 to $3.2 \%$ in 2008). HSS data indicate high $(>5 \%)$ levels and increasing trends in HIV prevalence among MSM in eight states of India during 2003-10. Analysis of 2010 HSS data indicates that HIV prevalence was $>10 \%$ in seven states. The factors associated with high HIV prevalence among MSM were being a kothi (the receptive partner in oral and anal sex, and typically with effeminate mannerisms) or a double-decker (both penetrative and receptive partner) rather than being a panthi (the penetrative partner in oral or anal sex) $(8 \%$ vs $4.3 \% ; P<0.05)$, being older than 25 years in age than their younger counterparts ( $9 \%$ vs $4.5 \% ; P<0.05)$, illiterate rather than literate MSM $(9.5 \%$ vs $6.9 \% ; P<0.05)$, and employed versus unemployed MSM $(9.1 \%$ vs $7.8 \% ; P<0.05)$.

Conclusion: While HIV prevalence among MSM at the national level is declining, it continues to remain high in some states and cities. Programs need to build on the successes in reducing HIV among female sex workers in order to control the high HIV prevalence among MSM in India.

Keywords: men who have sex with men, sexual behavior, program coverage, HIV, India

\section{Background}

Human immunodeficiency virus (HIV) prevalence rates are significantly higher for men who have sex with men (MSM) than for many other high-risk population groups in India. ${ }^{1}$ HIV prevalence among MSM was $4.43 \%$ in 2010 , the second highest rate after injecting drug users (IDUs), who are reported to have an HIV prevalence of $7.14 \%{ }^{2}$ Studies have also documented the high rates of syphilis among MSM: $14 \%$ in Tamil Nadu, ${ }^{3}$ 13\% in Chennai, ${ }^{4}$ 13\% in Andhra Pradesh, 8\% in Maharashtra, and 
$12 \%$ in Karnataka. ${ }^{3}$ In a study conducted in Mumbai using an Asian Epidemic Model, it was observed that new HIV infections among MSM are estimated to have declined by $82 \%$ during $2000-10$. The same study also quotes that the highest number of new infections in Mumbai city is going to be among MSM during 2011-17. ${ }^{5}$

Behavioral studies conducted among general male populations and sexually transmitted infection (STI) clinic attendees in different parts of India report prevalence of same-sex behavior ranging from $6 \%$ to $15 \%$, depending on the type of population studied. ${ }^{6-12}$ A survey of 527 truck drivers in northeast India reveals that $15 \%$ had sex with men. ${ }^{13}$ Another study conducted in 30 slums of Chennai documents that $5.9 \%$ of men had engaged in at least one same-sex encounter. ${ }^{7}$ A study of 2,910 males (aged 15-49 years) in five rural districts of five states (Haryana, Rajasthan, Uttar Pradesh, Orissa, and Karnataka) in India reveals that $9.5 \%$ of the young unmarried men who had sex in the past year had anal sex with another male; additionally, 3.1\% of married males who had extramarital sex in the past year reported anal sex with another male. ${ }^{14}$ A review paper on MSM research states that high rates of HIV and STIs among Indian MSM were due to a low education level, lack of access to basic health care, marginalization, social stigma, and the psychological consequences, which may lead to increased risk-taking behaviors, including commercial sex work and substance use. ${ }^{15}$

Evidence suggests a number of factors associated with MSMs' increased risk of HIV infection. They include sex with multiple sexual partners, inconsistent condom use, lack of knowledge of HIV risk, and negative attitudes toward safe sexual practices. ${ }^{16-18}$ A study of MSM in Andhra Pradesh found that $51 \%$ had engaged in sex with a female partner in the past 3 months, but condom use was $44 \%$ and $16 \%$ with their last male and female partner, respectively. ${ }^{6}$ A report from Bangalore found that $15 \%$ of MSMs were full-time commercial sex workers and 63\% engaged in same-sex relations for pleasure. ${ }^{12} \mathrm{~A}$ study of MSM in Chennai reports that $22 \%$ had unprotected anal sex and $36 \%$ had engaged in paid sex with another male. ${ }^{19}$ The surveillance conducted in Maharashtra reports that $75 \%$ of MSM engaged in anal sex, of whom $>20 \%$ did not use condoms with their sexual partners. $^{20}$

In the context that HIV prevalence among MSM continues to be high, this paper provides recent evidence on the HIV epidemiology and an overview of HIV prevention programs for MSM in India. Specifically, the paper aims to document national and state level data on current HIV prevalence and trends over time, MSMs' HIV-related sexual risk behaviors, and the national response to the epidemic. This information could help program implementers and policymakers plan, design, and implement appropriate programs in the future to contain the epidemic in this vulnerable group.

\section{Materials and methods}

Data on the levels and trends of HIV and associated risk behaviors among MSM are drawn from the following sources: 1) annual HIV Sentinel Surveillance (HSS), 2) high-risk group mapping and size estimation exercise, 3 ) integrated behavioral and biological assessment (IBBA), and 4) the Behavioral Surveillance Survey (BSS).

\section{Annual HIV Sentinel Surveillance}

The HSS in India was carried out in representative populations among various subgroups, including female sex workers (FSWs), MSM, IDUs, and patients attending STI clinics. Although the first HSS was conducted in the year 1985 by the Indian Council of Medical Research, the formal annual survey among high-risk groups started in 1998, after the National AIDS Control Organization (NACO) implemented it as part of monitoring the national level program. MSM sites were first included in the HSS in the year 2003 at three different locations. These surveillance sites were increased to 98 by the year 2010. The target sample size for the surveillance was set at $250 \mathrm{MSMs}$ at each sentinel site (usually held during June to August every year). Respondents for the surveillance are usually drawn from one of the following service points located in each of the sites: deaddiction centers, drop-in centers, and nongovernmental organization (NGO) clinics. With coverage of over $85 \%$ of the MSM population by the year 2006-07, little may be the bias with regard to generalization of the MSM epidemic using HSS data. However, for corroboration of HIV prevalence estimated using annual HSS, other data sources such as external surveys involving HIV testing, mapping of the populations, and factors associated with HIV risk among MSM are crucial.

\section{Mapping and size estimation exercise}

The mapping and size estimation exercise across different parts of India was first conducted in the year 2005. The key mapped populations included sex workers (females, men, and hijras/transgenders) and IDUs. The mapping estimate of the MSM population includes both high-risk MSM and transgender/hijra. Broad methodological steps included physical mapping of sites within each area, collecting data 
from secondary and tertiary key informants (people who are in contact with persons engaged in high-risk activities), collation of data from multiple sources, and its triangulation through interviews from selected individuals from within the high-risk community. The second round of mapping and size estimation was carried out in the year 2009. The lists produced in the year 2005 were validated by a research institute, and the estimates and hotspots were modified accordingly. Program data were also used to triangulate the validated estimates in the year 2009.

\section{Integrated behavioral and biological assessment}

Two rounds of IBBA were undertaken among MSM in 16 of the 83 Avahan intervention districts. Round one was conducted between November 2005 and December 2006 and round two between October and March 2009. From four high prevalence states, a total of 16 districts were selected for MSM survey in IBBA. Based on the size of the MSM population, four districts in Andhra Pradesh, five districts in Karnataka, three districts in Maharashtra, and four districts in Tamil Nadu were selected for the survey. However, the IBBA for FSW was conducted in six high prevalence states in 29 districts, which includes eight districts in Andhra Pradesh, five districts in Karnataka, six districts in Maharashtra, five districts in Tamil Nadu, two districts in Manipur, and three districts in Nagaland. The target sample size was 400 per district for MSM. Except in Maharashtra, where two districts were combined, and in Karnataka, four districts were combined for collecting a sample size of 400 MSM. Both rounds used identical methodologies. Probability-based sampling methods such as conventional cluster sampling and time-location sampling were used following a comprehensive sampling frame development exercise spanning the entire district. ${ }^{21}$ Both rounds of IBBA collected behavioral information and biological samples to test for STIs, including HIV. Fieldwork was conducted by research agencies under the guidance and supervision of the implementing state Indian Council of Medical Research Institute in Andhra Pradesh, the Indian National Institute of Nutrition, and the National AIDS Research Institute.

\section{Behavioral Surveillance Survey}

The BSS consists of systematic and repeated cross-sectional surveys of HIV and STI-related behaviors, socioeconomic conditions of the populations, and knowledge and attitudes on certain issues, including knowledge about transmission of HIV. Its major objective is to detect trends among selected high-risk population groups whose behavioral change can have the highest effect on the epidemic. NACO conducted the first national level BSS in the year 2001 and commissioned the second round of the BSS in 2006 to measure the changes in behavioral indicators. The third round of the BSS was conducted in the year 2009. A similar approach and tools were used for data collection across all different rounds of the survey. ${ }^{20,22}$

\section{Program monitoring data}

$\mathrm{NACO}$ and other program implementation partners have developed a computerized monitoring and information system for indicators of clinic service utilization, condom distribution, and outreach services over the years. For each targeted intervention program that has been funded, the NGOs or community-based organizations gather data on program indicators and report monthly achievement to each of the state AIDS control societies. State level data are collated centrally to monitor the program at the national level. Although the system for monitoring the program indicators was initiated in 2001, accurate and centralized data on program coverage and uptake of services were available for the period 2008-11.

\section{Ethics statement}

Secondary data that were available with the Department of AIDS Control (DAC/NACO), Ministry of Health and Family Welfare, Government of India, have been used for this study, and none of the data included any personal identifiers. Use of the secondary data and analyses for the present study was reviewed and approved by the ethical review and data sharing committees of NACO, Government of India.

\section{Data presentation and analyses}

In this study, HIV prevalence and other behavioral surveillance data have been presented separately for each group of states in order to compare the epidemic trend by geographic variability in the HIV risk environment. Broadly, the Indian states are grouped into four categories that capture 1) extent and availability of data, 2) severity of the epidemic and its drivers, and 3) status and comprehensiveness of response. This way of grouping of states also facilitates comparison of the present data with the earlier information published by Chandrasekaran et al. ${ }^{23}$ With a total population of 330 million, the states of Maharashtra, Karnataka, Andhra Pradesh, and Tamil Nadu (group I) account for nearly 1.07 million estimated HIV infections. ${ }^{24,25}$ Transmission is largely heterosexual. As a consequence of years of sustained large-scale prevention 
efforts, fairly comprehensive maps and size estimations of some high-risk groups are present, as well as behavioral, biological, and facility-based studies. ${ }^{24}$ As per the recent size estimation of MSM, group I states comprise 205,865 MSM, with a program coverage of 134,309 MSMs. $^{26}$

The second group of states (group II) comprises Manipur, Nagaland, and Mizoram, which have a combined population of 5.7 million, and accounts for an estimated 40,431 persons living with HIV. ${ }^{24,25}$ Transmission in these states is primarily via injecting drug use, and reasonable to extensive data on mapping and size estimation of some high-risk groups are present. As per the recent MSM size estimation, ${ }^{22}$ these states comprise 3,042 MSM, of which 1,592 are covered by the program. ${ }^{26}$

Delhi, Goa, Gujarat, Kerala, Puducherry, and West Bengal (group III), with a population of 204 million, form a loose grouping of states and account for 0.317 million estimated HIV infections. ${ }^{24,25}$ Transmission in these states appears to be heterosexual. Reasonable mapping and size estimation data for some high-risk groups are present, though with varying comprehensiveness across states, depending on the extent of programming. As per the recent MSM size estimation, ${ }^{22}$ these states comprise 127,335 MSM, with 90,923 covered by the program. ${ }^{26}$

The rest of India (group IV), consisting of states adjoining those in the first, second, and third groups, has a combined population of 627.5 million and accounts for 0.654 million estimated HIV infections. ${ }^{24,25}$ Transmission in these states is most likely heterosexual, although mapping of high-risk groups is probably not comprehensive, as evidenced from the limited extent of HIV programming. As per the recent MSM size estimation, ${ }^{22}$ these states have 90,803 MSM and 47,607 are covered by the program. ${ }^{26}$

\section{Results}

The data presented in this section were compiled from multiple sources. However, the data of the national HSS were used extensively for presenting results on background characteristics of MSM, HIV prevalence, and sexual risk behaviors, as it has a systematic three rounds of data and it is the only source that has the most recent information.

\section{Background characteristics}

The estimated MSM population showed uneven distribution of its size across different groups of states in India. The estimates suggest that the number of MSM in group I, III, and IV states was 0.205 million, 0.127 million, and 0.090 million, respectively, whereas the northeastern states in group II were estimated to have only 3,042 MSM. The mean age of MSM across Indian states ranged between 27 and 29 years. The proportion of ever married MSM varied across state groups, ranging between $18 \%-53 \%$ and $24 \%-56 \%$ in group I and III states, respectively, and was 38\% in Uttar Pradesh, the largest northern state of India. The percentage of illiterates among MSM was low, particularly in groups II and III states. The majority of MSM self-identify as either kothi (the receptive partner in oral and anal sex, and typically with effeminate mannerisms) or double-decker (both penetrative and receptive partner in oral and anal sex). The percentage of MSM who self identified as kothi was highest in group II states (84\%) and lowest in group IV states (34.1\%). Furthermore, in group IV states, two-fifths (40\%) of MSM self-identified themselves as panthi (the penetrative partner in oral and anal sex).

\section{HIV prevalence and trends}

As per the HSS 2010 data, HIV prevalence among MSM is considerably high $(>5 \%)$ in most of the group I, II, and III states, except for Kerala (0.4\%), Puducherry (1.2\%), Gujarat (3\%), and Tamil Nadu (2.41\%) (Table 1). Almost all the group IV states have recorded lower levels $(<5 \%)$ of HIV prevalence among the MSM population.

Overall, HIV prevalence among MSM has decreased at the national level, from $8.5 \%$ in 2003 to $4.43 \%$ in $2010-11$ (Figure 1). Almost all of the group I, II, and III states have shown a declining trend in HIV prevalence, although the proportion has been varied across the states. However, the low prevalence states of Punjab $(0.4 \%$ in 2007 to $2.1 \%$ in 2010-11) and Bihar (0\% in 2007 to $4.2 \%$ in 2010-11) have shown rising trends since 2007 (Figure 2). The declining trend in HIV prevalence also correlated with the declining trend in the prevalence of STIs (syphilis, NG, and CT) in almost all states in group I, II, and III (Table 1). The reported proportion of MSM suffering from at least one STI symptom also declined in all the states in 2009 compared with 2006.

\section{HIVIAIDS knowledge and sexual behavior of MSM}

Knowledge about HIV transmission and prevention among MSM has varied significantly between different studies and between states (Table 2). According to the data from the BSS conducted in 2009, MSM in some states have shown to have higher and more accurate knowledge of HIV and its transmission and prevention than the MSM in other states. For instance, in group I states, a greater proportion of MSM from the state of Tamil Nadu (32\%) reported comprehensive 


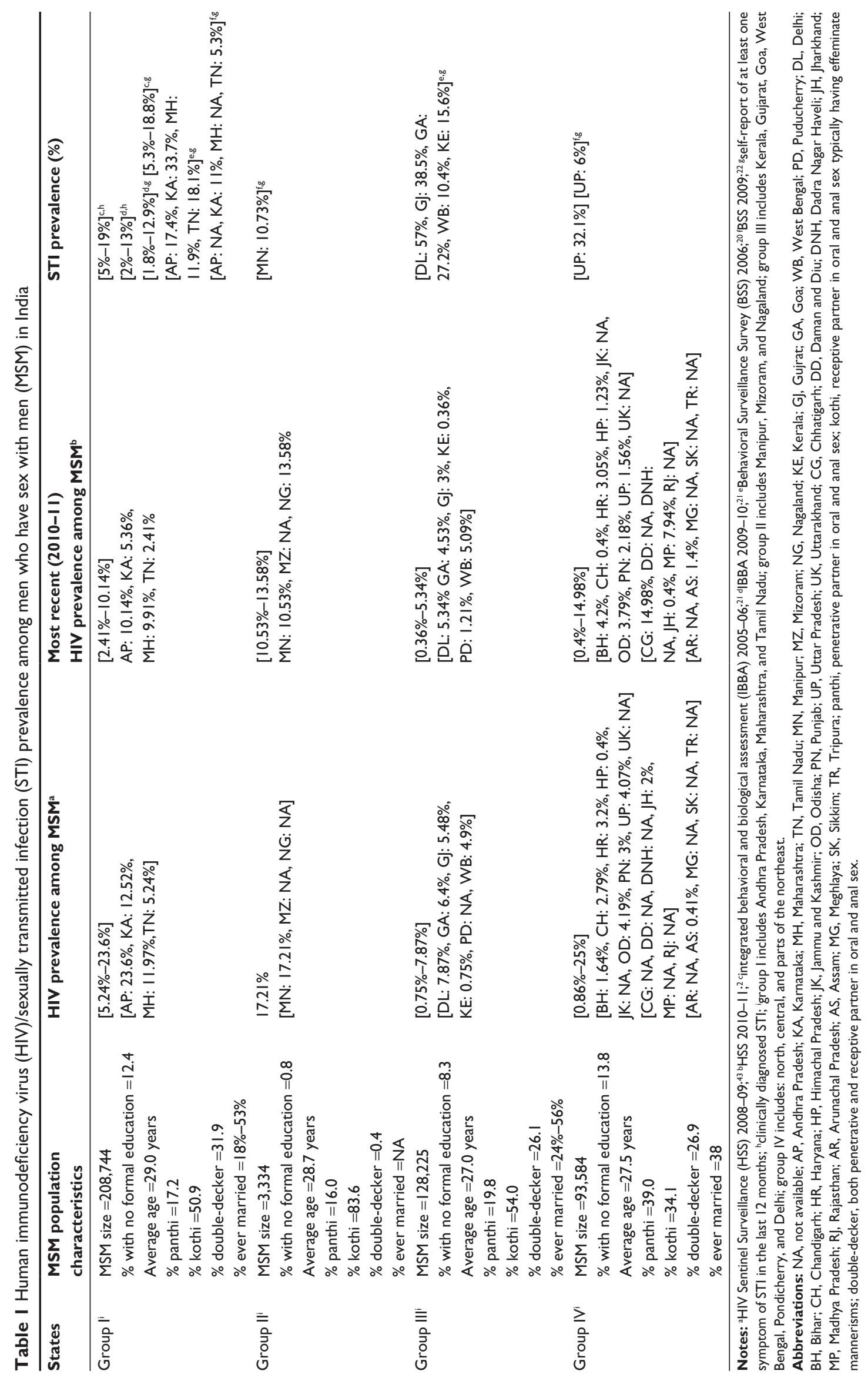




\section{Mean HIV prevalence (\%) among MSM}

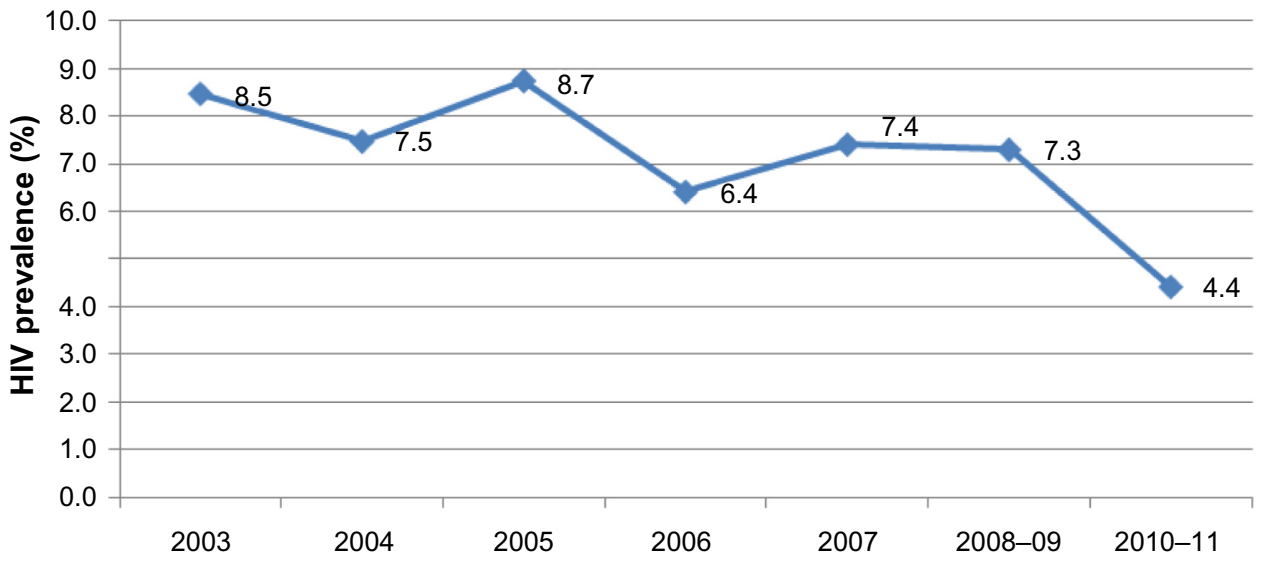

Figure I Trend of mean human immunodeficiency virus prevalence (\%) among men who have sex with men in India.

and correct knowledge about HIV, as compared with MSM in Karnataka (22\%) or Andhra Pradesh (57\%), as per BSS 2009. The proportion of MSM who reported comprehensive correct knowledge about HIV in Manipur from the group II states is $30.3 \%$. In group IV states, $21 \%$ of MSM from Uttar Pradesh report having correct knowledge about HIV transmission.

Further, the proportion of MSM reporting condom use the last time they engaged in sex with commercial or noncommercial male partners also varied across states. Recent data from the BSS 2009 show that condom use is significantly higher in group I states (ranging between 91\% in Maharashtra and 100\% in Andhra Pradesh and Karnataka for commercial sex partners and between 89.3\% in Maharashtra and 97\% in Andhra Pradesh for noncommercial sex partners). There were rates of $72 \%$ and $69.5 \%$ for commercial and noncommercial sex partners, respectively, in Manipur (group II), while, as per BSS 2006 , the proportion was $92 \%$ and $76 \%$ for commercial and noncommercial sex partners respectively in Uttar Pradesh (group IV).
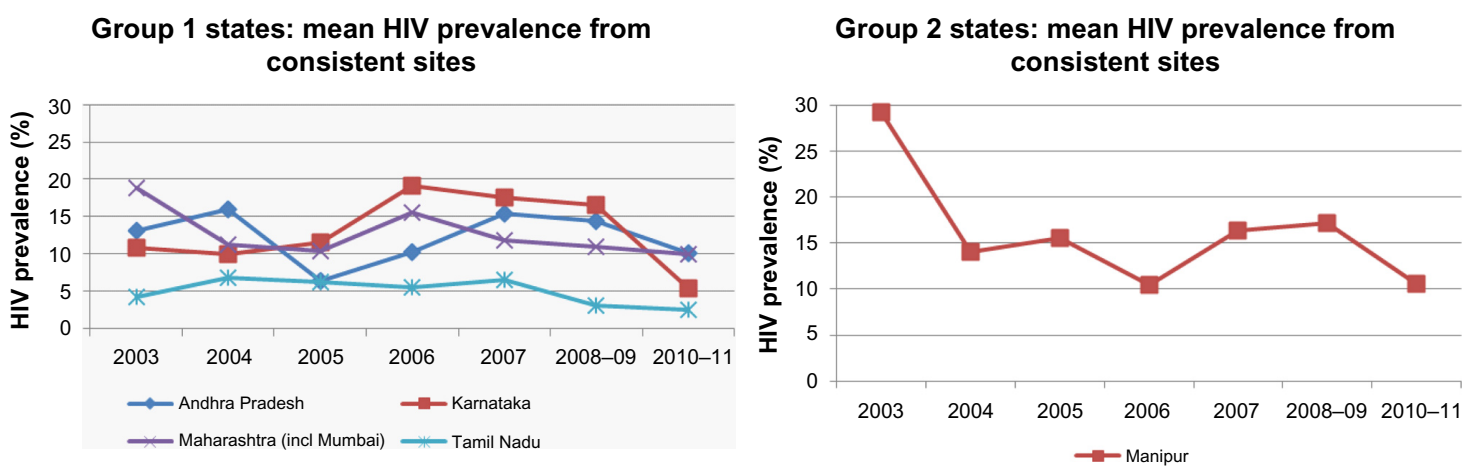

Group 3: mean HIV prevalence from consistent sites
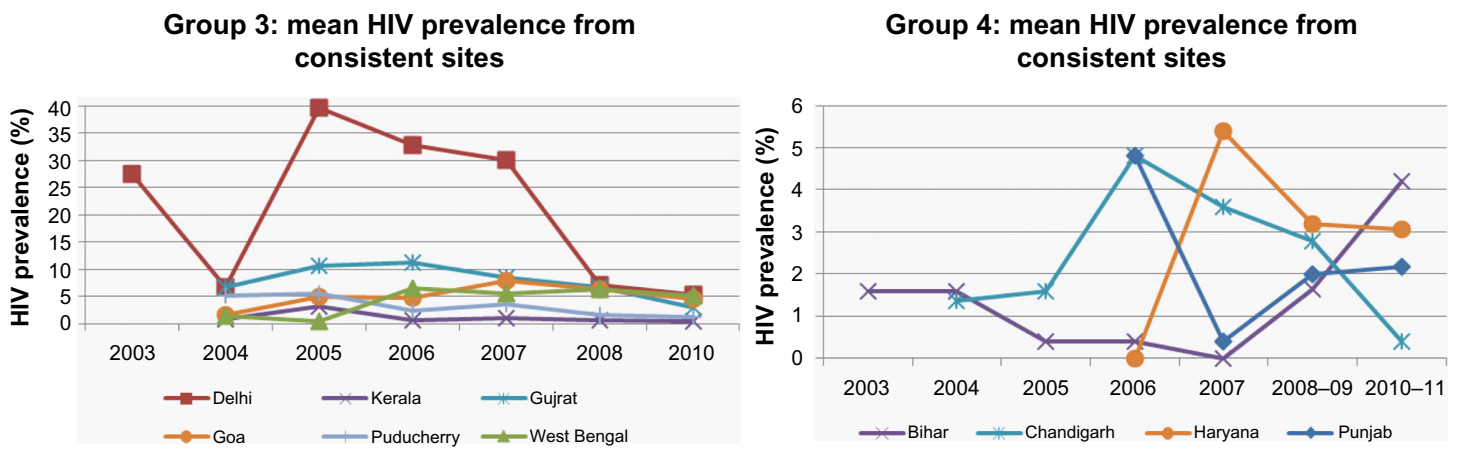

Figure 2 State-wise trend of human immunodeficiency virus (HIV) prevalence (\%) of men who have sex with men from consistent HIV surveillance sites in India. 


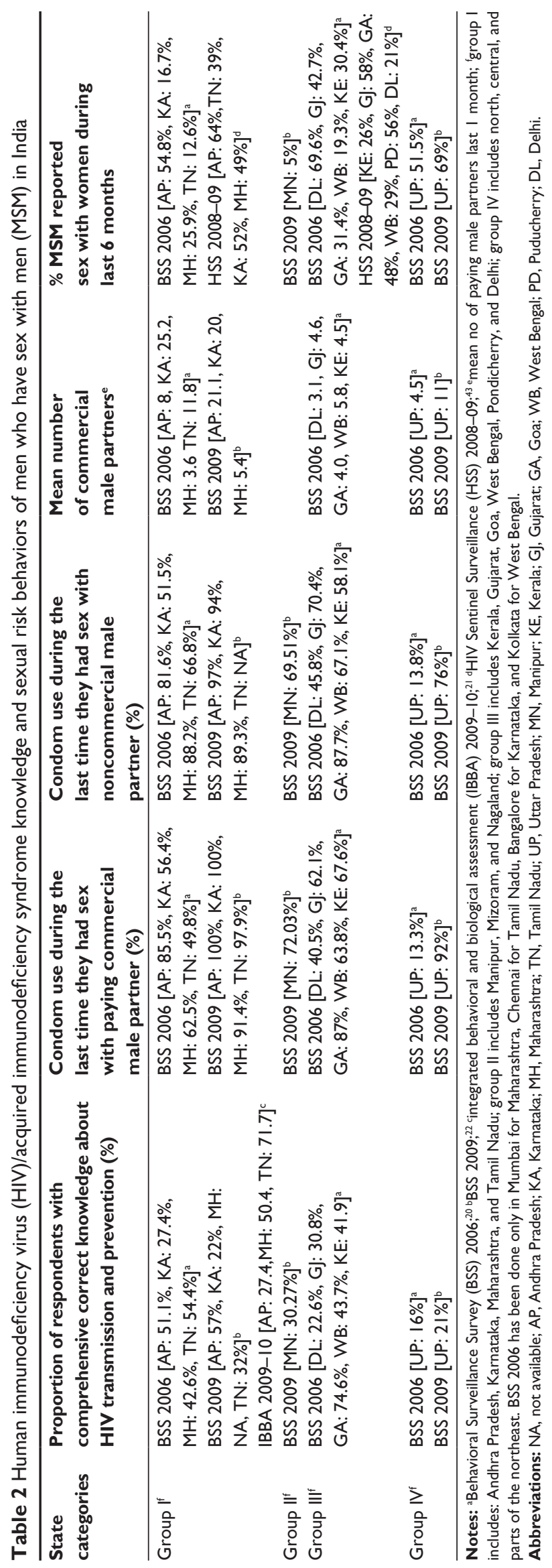

Comparison between BSS 2006 and 2009 data indicates a relative increase in condom use at last sexual encounter with commercial male partners with time. For example, in Andhra Pradesh, the proportion rose from 86\% in 2006 to $100 \%$ in 2009 , and in Maharashtra it increased from $63 \%$ to $91 \%$. Similarly, condom use during the last time they engaged in sex with a noncommercial partner also increased between 2006 and 2009. A higher proportion of respondents (group I) in $2009(89 \%-97 \%)$ than in $2006(67 \%-88 \%)$ reported using a condom at last sexual encounter with a noncommercial partner.

The mean number of commercial sexual partners in group I states was the highest in the state of Karnataka (25 partners in 1 month) and was lowest in Maharashtra (four partners in 1 month) as per BSS 2009. The mean number of commercial partners in group III states was three to six and for group IV states (Uttar Pradesh) was eleven, as observed in BSS 2006. The proportion of MSM having sex with women at least once in the past 6 months is $>50 \%$ in some of the states (being $64 \%$ and $52 \%$ in group I states of Andhra Pradesh and Karnataka respectively, and 58\% and $56 \%$ in the group III states of Gujarat and Puducherry, respectively, as per HSS 2008-09). Manipur from group II states reported the lowest (5\% as per BSS 2009), while Uttar Pradesh from group IV states was the highest (69\% as per BSS 2009). Moreover, the comparison between BSS 2006 and HSS 2008-09 suggests an increased percentage of MSM having sex with female partners.

\section{Current national response to the MSM epidemic}

Table 3 provides a description of data related to program coverage and its activities, compiled from multiple sources. Of the total estimated denominator for MSM in India, the national program through targeted intervention projects has covered $69 \%(2010-11)$ of MSM and transgenders. Coverage varied between $38 \%$ and $100 \%$ within group I states, between $76 \%$ and $100 \%$ within group II states, between $32 \%$ and $100 \%$ in group III states, and between $0 \%$ and $100 \%$ in group IV states. The estimated coverage has increased over time as the number of targeted interventions has increased from 31 in 2004-05 to 155 in $2010-11$. For example, the estimated coverage of MSM increased from $37 \%$ in 2004-05 to 64\% in 2010-11 in the four southern high prevalence states (group I). Similarly, the estimated proportion of condoms distributed to MSM rose from $2009-10$ to $2010-11$, ranging from $13 \%$ to $94 \%$ in group I states, $17 \%-46 \%$ in group II states, $16 \%-100 \%$ in group III states, and $0 \%-56 \%$ in group IV states. 


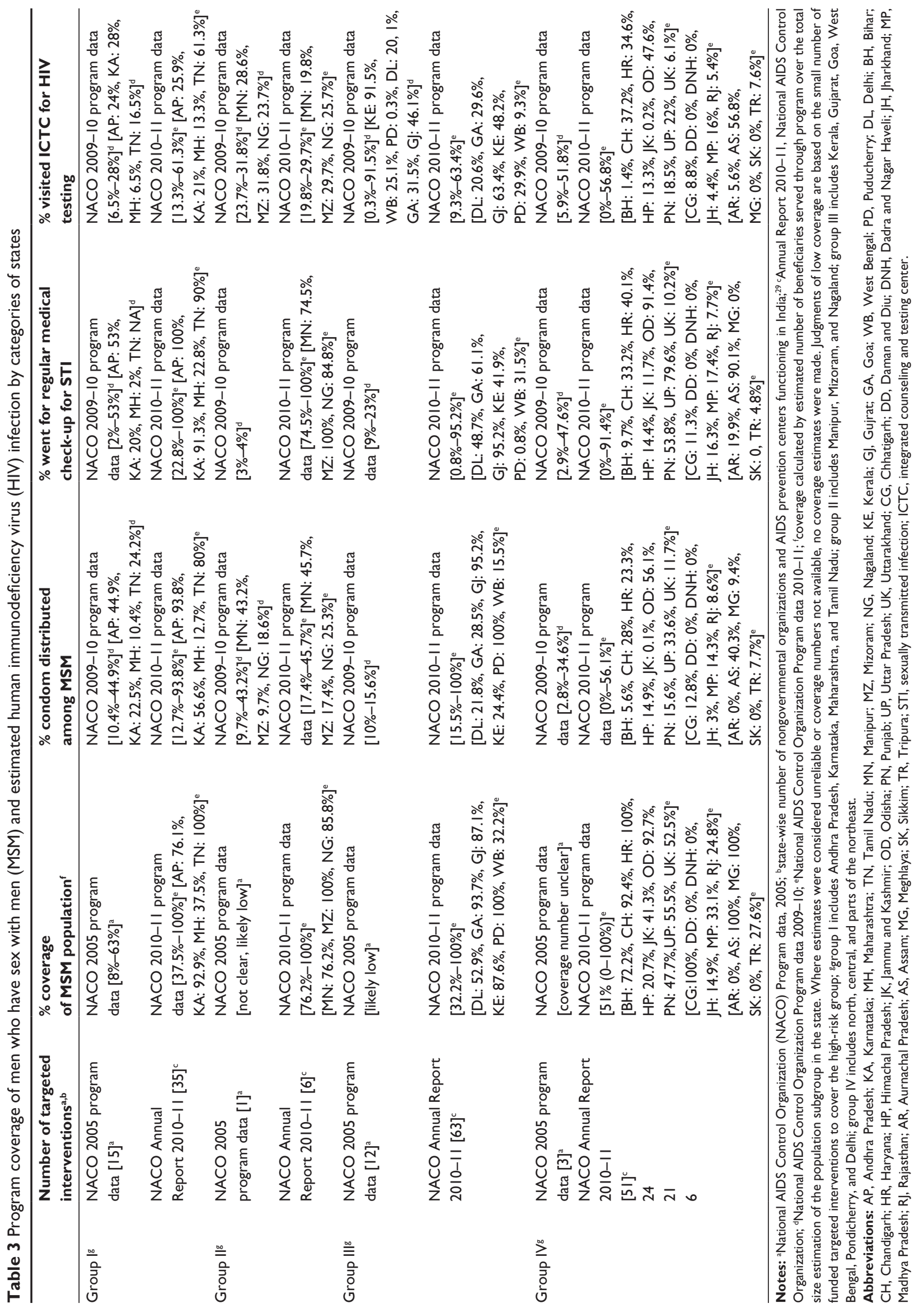


A higher proportion of MSM from all the states in 2010-11 reported at least one STI consultation or regular medical check-up in the past 3 months when compared with 2009-10 (improving from $2 \%-35 \%, 3 \%-4 \%, 9 \%-23 \%$, and $3 \%-48 \%$ in $2009-10$ to $23 \%-100 \%, 75 \%-100 \%, 1 \%-95 \%$, and $0 \%-92 \%$ in $2010-11$ in the group I, II, III, and IV states, respectively). Similarly, the proportion of MSM visiting an integrated counseling and testing center for HIV testing also increased over time from 2009-10 to 2010-11 in many states, though marked variations noted across states, with a range of $0 \%-63 \%$ across states.

\section{Discussion}

While overall HIV prevalence among high-risk population groups - including FSW and MSM - showed a decline in the past decade in India, some geographic areas (states/districts in group I, II, and III) still have a considerably high ( $>5 \%$ ) HIV prevalence among MSM. Indian states such as Andhra Pradesh, Delhi, Karnataka, Maharashtra, Manipur, and West Bengal have consistently shown a high HIV prevalence $(>5 \%)$ among MSM during the last three rounds of HSS., ${ }^{2,27,28}$ States like Madhya Pradesh, Chhattisgarh, and Nagaland have also shown high HIV prevalence among MSM, as per the HSS data in 2010-11. As per the program coverage, data presented in this paper suggest that the program to contain the HIV epidemic among MSM has received greater attention in the past 5 years in most states, particularly in group I states. This was a possibility due to continued effort of the National AIDS Control Program Phase III, which was initiated in 2006 and which emphasised data gathering, evidence-based program planning, and implementation of various educational activities for MSM.

The overall decline in HIV prevalence among MSM could be partially attributed to an increased program focus in group I states through its evidence-based program planning. The programs implemented by developmental agencies in the group I states had the strategy of keeping the community at the center in planning, execution, and monitoring of the program. Another important factor for its success in group I may be ascribed to its focus on program implementation through peer-led community outreach. This approach was based on the premise that trained members of high-risk groups are more aware of the needs of their communities, and peers can reach and deliver services to the community more effectively than people who are not members of these communities. ${ }^{28}$ Further, the interventions for MSM across India have established drop-in centers to provide safe spaces and basic medical services. ${ }^{29}$ The clinic services for MSM include presumptive treatment for STIs alongside syndromic management and regular screening, promoting referrals for HIV testing, counseling, treatment, and care. ${ }^{30}$ Because many medical professionals were not used to treating MSM, training was provided to various health care practitioners on diagnosis and management of STIs among the MSM population. Several innovations were made in the delivery of these services from one geographical area to another, particularly in the states under group I. Some of those innovations included sensitization of, and partnership with, government health facilities in rural/semiurban areas, identification and training of community preferred treatment providers, and regular health camps using mobile vans. ${ }^{28}$

Under the guidance of NACO, the NGOs and communitybased organizations are at the front line of HIV/AIDS prevention and service delivery efforts through targeted interventions in India. However, there are some states within group III and IV that require saturated coverage of MSM with renewed focus under an HIV prevention program. Taking lessons learnt from states in group I, the methods of implementation of intervention in these states could include 1) engaging the community to map and bring large numbers of MSM into the program, 2) providing safe spaces for MSM, 3) facilitating an enabling environment for reduction of violence and arrests from police, and 4) mobilizing the community of MSM to participate in, design, and implement the targeted intervention under the supervision of an NGO. Explicit attention should be paid toward the use of MSM communities as peers in local program implementation for distribution of condoms and accompanying others to health facilities and STI clinics. Further, it is important to implement high-level advocacy meetings with police and media to promote the use of MSM-friendly services.

It is also important to focus on increasing the rate of condom use by MSM for sex with female partners, who are generally perceived as low risk. This may be difficult to achieve and sustain, however, because the desire for children may compete with the concern for protecting partners from HIV infection. Further, the HIV infection in the general population will continue to increase unless condom use with high-risk partners of MSM becomes more consistent. ${ }^{31}$

\section{Way forward}

Although the results indicate an increase in condom use among MSM in some states, HIV prevalence continues to be high in those states. The priority is therefore to leverage and build on the comprehensive set of strategies that led to success in reducing HIV among the FSW population in order to reduce 
HIV among MSM in the selected states. The published work from India on successful strategies among the FSW population included one or all of the following: increased coverage, peer-led service delivery and education, condom social marketing and distribution, training in the skills necessary for their negotiation to condom use and utilization of services, ${ }^{32-34}$ community engagement, and networking at all levels. ${ }^{35,36}$ In India, HIV prevention interventions have placed FSWs at the center of the programs and, in fact, have used them as peer educators at a micro level to the community boards at the macro level to scale up the HIV prevention program. ${ }^{37}$ For instance, the interventions in selected states of India have shown that the FSW community were represented in various forums of the HIV prevention projects, including crisis response, program planning, and district/state committees on HIV prevention programs. ${ }^{38}$ This initiative has facilitated the FSW community's ownership of the HIV prevention program. And there was evidence to show that such community-led structural interventions helped reduce the rates of HIV and STIs, ${ }^{39}$ stigma, and violence, and have improved utilization of services from public health care facilities, ${ }^{40}$ safe sex behaviors, and self- and collective empowerment. ${ }^{41,42}$

While there were some similar interventions undertaken for the MSM population in selected parts of India, those interventions were less effective due to the fact that MSM operate in an environment in which it is considered not only illegal and thus "hidden" but also socially abhorrent. Notwithstanding, there was some evidence-based development and implementation of MSM community-led interventions for the HIV prevention in selected cities in India. ${ }^{41}$ Lessons learnt from such interventions and the program experience suggest that targeted interventions with intensive peer-led education and condom promotion, building an enabling environment by networking with stakeholders at different levels, promoting community-led program planning and execution, and active linkages to integrated testing and treatment services may help to further reduce HIV. Further, involving communities actively in district and state program units and provision of project-based STI clinics may further HIV risk reduction among MSM. Efforts should also be made to address the legal barriers that prevent expanded outreach of HIV services to MSM, and to address the stigma and discrimination faced by MSM in the country.

Further, as the program marches ahead, sustaining the coverage and intensity of prevention interventions where declines in HIV prevalence have been achieved is critical. The existing interventions shall make concerted efforts to empower MSM for access to health care and other services, strengthen networking, and address specific needs of the community such as ensuring access to thicker condoms and lubricants, and treatment of anal STIs. Interventions should be implemented to bring about behavior change through innovative communication strategies and materials, and to provide them with access to preventive care, support, and treatment in efforts to stop the HIV spread among MSM and their sexual partners.

\section{Acknowledgments}

This paper was written as part of a mentorship program to the first author, under the Knowledge Network Project of the Population Council, which is a grantee of the Bill and Melinda Gates Foundation through Avahan, its India AIDS Initiative. The views expressed herein are those of the authors and do not necessarily reflect the official policy or position of the National AIDS Control Organization or the Bill and Melinda Gates Foundation or the Population Council.

\section{Disclosure}

All authors verify that they have no conflicts of interest regarding this work.

\section{References}

1. National AIDS Control Organization, Deparatment of AIDS Control, Ministry of Health and Family Welfare, Government of India. Annual Report 2010-2011. New Delhi: NACO, Ministry of Health and Family Welfare, Government of India; 2012.

2. National AIDS Control Orgainsation, Department of AIDS Control, Ministry of Health and Family Welfare, Government of India. HIV Sentinel Surveillance 2010-2011: A Technical Brief. New Delhi: Government of India; 2011.

3. Brahmam GN, Kodavalla V, Rajkumar H, et al. Sexual practices, HIV and sexually transmitted infections among self-identified men who have sex with men in four high HIV prevalence states of India. AIDS. 2008; 22 Suppl 5:S45-S57.

4. Newman PA, Chakrapani V, Cook C, Shunmugam M, Kakinami L. Correlates of paid sex among men who have sex with men in Chennai, India. Sex Transm Infect. 2008;84(6):434-438.

5. Mishra RM, Dube M, Sahu D, Saggurti N, Pandey A. Changing epidemiology of HIV in Mumbai: an application of the Asian epidemic model. Glob J Health Sci. 2012;4(5):100-112.

6. Dandona L, Dandona R, Gutierrez JP, Kumar GA, McPherson S, Bertozzi SM. Sex behaviour of men who have sex with men and risk of HIV in Andhra Pradesh, India. AIDS. 2005;19(6):611-619.

7. Go VF, Srikrishnan AK, Sivaram S, et al. High HIV prevalence and risk behaviors in men who have sex with men in Chennai, India. $J$ Acquir Immune Defic Syndr. 2004;35(3):314-319.

8. Gupta A, Mehta S, Godbole SV, et al. Same-sex behavior and high rates of HIV among men attending sexually transmitted infection clinics in Pune, India (1993-2002). J Acquir Immune Defic Syndr. December 1, 2006;43(4):483-490.

9. Hernandez AL, Lindan CP, Mathur M, et al. Sexual behavior among men who have sex with women, men, and Hijras in Mumbai, India: multiple sexual risks. AIDS Behav. 2006;10(Suppl 4):S5-S16. 
10. Joint United Nations Programme on HIV/AIDS. India MSM Country Snapshots - Country Specific Information on HIV, Men Who Have Sex With Men (MSM) and Transgender People (TG): Joint United Nations Programme on HIV/AIDS. New Delhi, India: UNAIDS; 2010.

11. Kumta S, Setia M, Jerajani HR, Mathur MS, RaoKavi A, Lindan CP. Men who have sex with men (MSM) and male-to-female transgender (TG) in Mumbai: a critical emerging risk group for HIV and sexually transmitted infections (STI) in India. 14th International AIDS Conference; Barcelona, Spain; 2002.

12. Phillips AE, Boily MC, Lowndes CM, et al. Sexual identity and its contribution to MSM risk behavior in Bangaluru (Bangalore), India: the results of a two-stage cluster sampling survey. $J$ LGBT Health Res. 2008;4(2-3):111-126.

13. Ahmed SI. Truck drivers as a vulnerable group in North East India. Berlin 1993.

14. Verma RK, Collumbien M. Homosexual activity among rural Indian men: implications for HIV interventions. AIDS. 2004;18(13):1845-1847.

15. Patel VV. Addressing health issues of MSM in India. Indian J Med Res. 2012;136:563-570.

16. Shinde S, Setia MS, Row-Kavi A, Anand V, Jerajani H. Male sex workers: are we ignoring a risk group in Mumbai, India? Indian $J$ Dermatol Venereol Leprol. 2009;75(1):41-46.

17. HIV Prevention for Men Who Have Sex With Men: Issue Brief No 4. New York: The Foundation for AIDS Research; 2006.

18. Mumtaz G, Hilmi N, McFarland W, Kaplan RL, Akala FA. Are HIV epidemics among men who have sex with men emerging in the Middle East and North Africa? A systematic review and data synthesis. PLoS Med. 2011;8(8):e1000444.

19. Thomas B, Mimiaga MJ, Menon S, et al. Unseen and unheard: predictors of sexual risk behavior and HIV infection among men who have sex with men in Chennai, India. AIDS Educ Prev. 2009;21(4):372-383.

20. National AIDS Control Organization (NACO) Deparatment of AIDS Control, Ministry of Health and Family Welfare, Government of India. Behavioral Surveillance Survey (BSS) 2006. New Delhi: NACO, Ministry of Health and Family Welfare, Government of India; 2006.

21. National AIDS Research Institute, FHI 360. AVAHAN, Round 2, National Summary Report, Integrated Behavioral and Biological Assessment (IBBA) 2009-2010. New Delhi: National AIDS Research Institute, FHI 360;2009-2010.

22. National AIDS Control Organization (NACO) Ministry of Health and Family Welfare, Government of Inda. Behavioral Surveillance Survey (BSS) 2009. New Delhi: NACO, Ministry of Health and Family Welfare, Government of India; 2009

23. Chandrasekaran P, Dallabetta G, Loo V, Rao S, Gayle H, Alexander A. Containing HIV/AIDS in India: the unfinished agenda. Lancet Infect Dis. 2006;6(8):508-521.

24. National AIDS Control Organization (NACO), Government of India, National Institute of Medical Statistics (NIMS), Government of India Technical Report India HIV Estimates. New Delhi: NACO, NIMS; 2011.

25. Registrar General of India and Census Commissioner, Government of India. State-Wise Total Population in India. New Delhi: Government of India; 2011.

26. National AIDS Control Organization (NACO), Deparatment of AIDS Control, Ministry of Health and Family Welfare, Government of India. Annual Report 2009-2010. New Delhi, Ministry of Health and Family Welfare, Government of India; 2009-2010.

27. National AIDS Control Organization (NACO), Deparatment of AIDS Control, Ministry of Health and Family Welfare, Government of India. HIV Sentinel Surveillance Technical Report 2007. New Delhi: NACO, Ministry of Health and Family Welfare, Government of India; 2007.

28. Bill and Melinda Gates Foundation. Breaking Through Barriers: Avahan's Scale-up of HIV Prevention Among High-risk MSM and Transgenders in India. New Delhi; 2010.
29. National AIDS Control Organization (NACO). State-wise Number of $N G O s$ and AIDS Prevention Centres Functioning in India. New Delhi; Aug 2005 .

30. National AIDS Control Orgainsation, Deparatment of AIDS Control, Ministry of Health and Family Welfare, Government of India. National Guidelines on Prevention, Management and Control of Reproductive Tract Infection Including Sexually Transmitted Infections. New Delhi: NACO, Ministry of Health and Family Welfare, Government of India.

31. Thomas B, Mimiaga MJ, Kumar S, Swaminathan S. HIV in Indian MSM: Reasons for a Concentrated Epidemic and Strategies for Prevention. Chennai, India; 2011.

32. Alary M, Banandur P, Rajaram SP, et al. Increased HIV prevention program coverage and decline in HIV prevalence among female sex workers in south India. Sex Transm Dis. 2014;41(6):380-387.

33. Wheeler T, Kiran U, Dallabetta G, et al. Learning about scale, measurement and community mobilisation: reflections on the implementation of the Avahan HIV/AIDS initiative in India. J Epidemiol Community Health. 2012;66 Suppl 2:ii16-ii25.

34. Galavotti C, Wheeler T, Kuhlmann AS, et al. Navigating the swampy lowland: a framework for evaluating the effect of community mobilisation in female sex workers in Avahan, the India AIDS Initiative. J Epidemiol Community Health. 2012;66 Suppl 2:ii9-ii15.

35. Kuhlmann AS, Galavotti C, Hastings P, Narayanan P, Saggurti N. Investing in communities: evaluating the added value of community mobilization on HIV prevention outcomes among FSWs in India. AIDS Behav. 2014;18(4):752-766.

36. Blankenship KM, West BS, Kershaw TS, Biradavolu MR. Power, community mobilization, and condom use practices among female sex workers in Andhra Pradesh, India. AIDS. 2008;22 Suppl 5: S109-S116.

37. Sadhu S, Manukonda AR, Yeruva AR, Patel SK, Saggurti N. Role of a community-to-community learning strategy in the institutionalization of community mobilization among female sex workers in India. PLoS One. 2014;9(3):e90592.

38. Beattie TS, Mohan HL, Bhattacharjee P, et al. Community mobilization and empowerment of female sex workers in Karnataka State, South India: associations with hiv and sexually transmitted infection risk. $\mathrm{Am}$ J Public Health. 2014;104(8):1516-1525.

39. Yadav D, Ramanathan S, Goswami P, et al. Role of community group exposure in reducing sexually transmitted infection-related risk among female sex workers in India. PLoS One. 2013;8(10):e78361.

40. Parimi P, Mishra RM, Tucker S, Saggurti N. Mobilising community collectivisation among female sex workers to promote STI service utilisation from the government healthcare system in Andhra Pradesh, India. J Epidemiol Community Health. 2012;66 Suppl 2: ii62-ii68.

41. Saggurti N, Mishra RM, Proddutoor L, et al. Community collectivization and its association with consistent condom use and STI treatmentseeking behaviors among female sex workers and high-risk men who have sex with men/transgenders in Andhra Pradesh, India. AIDS Care. 2013;25 Suppl 1:S55-S66.

42. Gaikwad SS, Bhende A, Nidhi G, Saggurti N, Ranebennur V. How effective is community mobilisation in HIV prevention among highly diverse sex workers in urban settings? The Aastha intervention experience in Mumbai and Thane districts, India. J Epidemiol Community Health. 2012;66 Suppl 2:ii69-ii77.

43. National AIDS Control Orgainsation, Ministry of Health and Family Welfare, Government of India. Annual HIV Sentinel Surveillance Country Report 2008-09. New Delhi: NACO; 2008-2009. 


\section{Publish your work in this journal}

HIV/AIDS - Research and Palliative Care is an international, peerreviewed open-access journal focusing on advances in research in HIV, its clinical progression and management options including antiviral treatment, palliative care and public healthcare policies to control viral spread. The journal welcomes original research, basic science,

clinical \& epidemiological studies, reviews \& evaluations, expert opinion \& commentary, case reports \& extended reports. The manuscript management system is completely online and includes a very quick and fair peer-review system. Visit http://www.dovepress.com/ testimonials.php to read real quotes from published authors.

Submit your manuscript here: http://www.dovepress.com/hivaids---research-and-palliative-care-journal 